\title{
Accelerator Magnet Designs Using Superconducting Magnetic Shields *
}

\author{
B. C. Brown \\ Fermi National Accelerator Laboratory \\ P.O. Box 500 \\ Batavia, Illinois 60510
}

October 1990

* Presented at the 1990 Applied Superconductivity Conference, Snowmass, Colorado, September 24-28, 1990. 


\title{
ACCELERATOR MAGNET DESIGNS USING SUPERCONDUCTING MAGNETIC SHIELDS
}

\author{
B. C. Brown \\ Fermi National Accelerator Laboratory * \\ P.O. Box 500 \\ Batavia, Illinois 60510
}

\begin{abstract}
Superconducting dipoles and guadrupoles for existing accelerators have a roil surrounded by an iron shichd. The shiseld lim. its the fringe ficld of the magnet while having minimal effect on the field slape and providing a small enhancement of the field strength. Shiclds using superconducling materials can be thithner and lighler and will not experience the potential of a large decentering force. Bundary conditions for these matcrials, material properties, mechanical force considerations, cryostat considerations and some possible geometrical configurations for superconducting shields will be described.
\end{abstract}

\section{Multipoles with Cylindrical Shields}

The magnetic field produced by a multipole coil within a cylindrical iron shield is subject to analysis by image methods. The fieldis and resulting forces are analyzed by Ilalback [1]. The resulting formulas will apply to the case with a diamagnetic shicld by an appropriate change of sign. For dipoles, we find that the field is given by

$$
B=B_{0}\left(1 \pm\left(\frac{a}{R}\right)^{2}\right)
$$

where $R$ is the shield radius and $a$ the coil effective radius and the plus sign applies for a perfect ferromagnetic shicld. Other approaches to shiclding design can be found $[2 \mid\{3\}$

When a superconducting coil is surrounded by an iron shell there is a weil known de-centering force between the coil and the shell. This is of considerable significance in design of cryostat systems since the allowance for an imperfect alignment requires the cryostat to withstand the forces generated. If the iron shield is to be held at a different temperature than the coil, the ability to reduce the conduction between the two parts will be limited by the requirement to support de-cculering forces. Since the image current is in the reverse direction for the diamagnetic shicld, an off-center coil will experience a restoring force rather than a decentering onc. The magnitude of these forces was calculated by Ilalbach [1] to be

$$
f=\frac{1}{2} \pi \mu(N+1) H^{2} \rho \delta z
$$

for the case in which iron saturation effects are ignored. This force is large in proportion to the enhancement songht from the iron shield.

\section{Superconducting Materials}

In Table 」 we list some of the materials which might be considered for magnetic shiclding applications. We note that successful

\footnotetext{
- Operaled by the Universilies Reseach Association under conlract with the I!. S. Department of Energy
}

Manuscript received September 24, 1990
Table 1: Some Superconducting Naterials

$\begin{array}{lll}\text { Material } & \text { Temperature } & \text { Useful Field } \\ \text { Niobium } & 4 K & 0.2 \mathrm{~T} \\ N b T i & 4 K & 5 \mathrm{~T} \\ N b_{3} S n & 10 K & 5 \mathrm{~T} \\ \text { High Temp SC } & 20-70 K & 0.2 \mathrm{~T}\end{array}$

magnets have been constructed with $N b T i$ but that the cost of this material is fairly high so its use would be restricted to applications in which this design provides some essential new feature. P'ure Niobium has the advantages associated with Type I superconductors: no flux penetration at all. This has been utilized in shiclding tubes in the past but is limited to relatively low fields even at helium temperatures. $\mathrm{Nb}_{3} S n$ has been difficult to use in magnets but as a shicld, its mechanical limitations may be more casily overcome. In addition, it may be possible to use it at a temperature near 10 degrees which could be suitable for the thermal shicld layer in a low temperalure cryostat. The possibilities for utilizing the new high temperature superconductors is more speculative but more exciting. It secms clear, for materials currently under developmenl, that their magnelic shielding properties at nitrogen temperatures are not interesting. However, it is quite possible that interesting shielding properties could be obtained at temperatures of 20 lo 30 degrees where intermediate temperalure thermal shields are very favorably designed into existing large magnets [4]. As developments continue for high temperature superconductors, olher alternatives may be developed.

Consider a circular cylinder of superconductor of an appropriate length and radius. The current required to shield a given magnetic field can be calculated by assuming that a current density $J_{c}$ is carried within a thickness $w$ near the surface of a superconductor at which the magnetic field parallel to the surface is $B$. Utilizing the usual Ampere's Law integral we find

$$
u=\frac{B}{\mu_{0} \cdot J_{\mathrm{c}}}
$$

For $N 6 T i$ and $N b_{3} S n$ we will take a value of $2000 \mathrm{~A} / \mathrm{mm}^{2}$ $\left(2 \times 10^{9} \mathrm{~A} / \mathrm{m}^{2}\right)$ while for the high temperature materials we will assume $100 \mathrm{~A} / \mathrm{mm}^{2}\left(10^{8} \mathrm{~A} / \mathrm{m}^{2}\right)$. Thus a shicld using $N b_{3} S n$ for $3 \mathrm{~T}$ would require $1.2 \mathrm{~mm}$ of material while it would require $1.6 \mathrm{~mm}$ of High Temperature material for shiciding $0.2 \mathrm{~T}$. Since the current carrying capacity of superconduclor improves when it is shielded, the outer portion of the shicld layer may be more effective, making this estimate conservative|3i. 
Table 2: Some Fields and Radii in the Effective Radius ApproxiCollider Detector with Dipole Analysis Magnet unation

$\begin{array}{llll}\text { B coil } & a & R(2 T) & R(0.2 \mathrm{~T}) \\ \text { Dipoles } & & & \\ & & & \\ 6 \mathrm{~T} & 4 \mathrm{~cm} & 7 \mathrm{~cm} & 22 \mathrm{~cm} \\ 8 \mathrm{~T} & 4 \mathrm{~cm} & 8 \mathrm{~cm} & 25 \mathrm{~cm} \\ 1.3 \mathrm{~T} & 4 \mathrm{~cm} & 10 \mathrm{~cm} & 32 \mathrm{~cm} \\ & & & \\ \text { Quads } & 1 & & \\ 6 \mathrm{~T} & 4 \mathrm{~cm} & 5.7 \mathrm{~cm} & 12.1 \mathrm{~cm} \\ 8 \mathrm{~T} & 4 \mathrm{~cm} & 6.3 \mathrm{~cm} & 13.7 \mathrm{~cm} \\ 13 \mathrm{~T} & 4 \mathrm{~cm} & 7.5 \mathrm{~cm} & 16.1 \mathrm{~cm}\end{array}$

\section{Magnet Configurations and Fields}

Fur a multipole magnet of symmetry $2 \mathrm{~N}(\mathrm{~N}=1$ is a dipole) we know that as we move outward away from the coil the field is completely dominated by the lowest order harmonic component. In designing a shield, we will be satisfied with such single term expansions (The problem is to select a useful effective radius.) The peak field at radius $R$ is given by the formula

$$
B=B_{o}\left(\frac{a}{h}\right)^{N+1}
$$

where $B_{n}$ is not very different than the field at the effective radius a. In Table 2 we illustrale a few interesting rases.

With these numbers in mind, we suggest three applications in which a superconducting shield may offer important advantages over an iron shicld.

1. For very ligh field arcelerator dipoles, one can avoid the decentering force, the weight (which impacts the cryostat design) and non-uniform field of a saturated iron shield by using a supetconducting shell. The field enlancement from an iron shield will be a relatively smaller advantage than for magnets which provide 4-6 Tesla fields (see section on dipoles).

2. For quadrupoles in a p-p colliding leam collision region, as the transverse separation between orbits decreases we must chnose between quadrupoles which are nearby but independent and a shared quadrupole (large aperture). The iron required for shielding a quadrupole pair which produces 2 $T$ at the iron surface is likely to have a thickness of several $\mathrm{cm}$ whereas we have suggested above that a few $\mathrm{mm}$ of $\mathrm{Nb}_{3} \mathrm{~S} n$ might provide the same shielding. Thus, one may have quadrupoles with equal strength and apcrture but smaller orbit to orbit separation using superconducting shields. For quadrupoles, one cannot achieve a substantial field enhancement with iron (or decrement with superconductor) because the field naturally falls with radius more quickly than for dipoles.

3. If a colliding detector is to be based upon a dipole field, one will need a compensating dipole within the straight section to cancel the dipole bending of the detector. Typicai large aperture experiments will wish to exploit all of the available angular regions to look for particles. We illustrate this with Fig 1. The angular region $\phi$ blocked by the compensating dipoles is determined by their overall cadius $R$ and distance

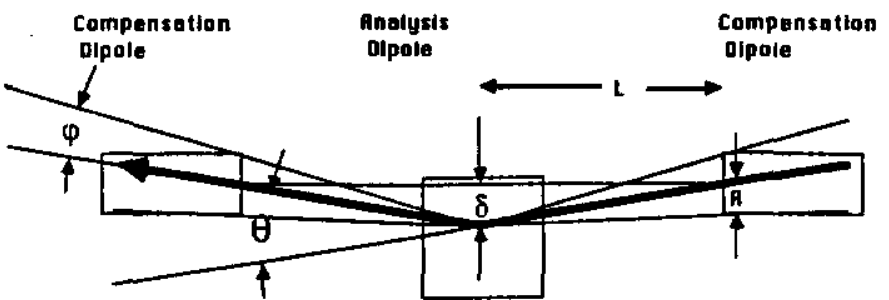

$\theta \quad$ Bend Angle

$\varphi \quad$ Minimum Detector Angle

$\delta$ Beam ofrsat (with analysis dipale offl

l Detector open Length

B Compensation Oipole Uacuum Con Aadius

$$
\delta=\theta \text { L }=(\theta / \varphi) \text { В }
$$

Figure 1: Compensalion Dipotes for a Collider Detector with Dipole Analysis Magnet illustrating the advantages of small overall magnet radius achieved with a Superconducting Shield

from the interaction point $L$ giving $\phi=R / L$. Assuming that the analysis dipole must operate at fields from zero to its maximum, the beam pipe must be clear for a radial dis1.ance $\delta$ determined by the distance $L$ and the bend strength $\int B d l$ of the analysis magnet. Maintaining a small $\delta$ allows the experiment to examine particle decays very close to the interaction point. Reducing the overall radius $R$ of the compensating dipoles will allow one to reduce the required beam pipe size in the detector. The cost of providing a superconlucting shield at $f K$ inay be a very desirable trade-of in this situation.

\section{Effects of Shields on the Maximum Field in Superconducting Dipole Magnets}

As discussed above, a supcrconducting magnet design will realize an enhanced field at a fixed current by adding an iron shield. At the maximum current for which the iron is ursaturated, it will add about a Tesla to the central field of a dipole. A perfect superconducting shield of the same radius will result in a similar decrement to the field. However, ignoring the costs of power supply changes (small), the proper comparison of such designs is at the point for each design for which the coil reaches its current carrying limits. A suitable way to explore this is shown in Fig 2 in which we show the body field (solid diagonals) and maximum field at the coil (dashed diagonals) for three magnet options. Each has a coil with inner radius of $3.5 \mathrm{~cm}$. When required, the shield has an inner radius of $9.624 \mathrm{~cm}$. The three cases include an iron shicld (assumed unsaturated), no shield, and a superconducting shield. The superconducting cable properties at either $1.8 \mathrm{~K}$ or $4.35 \mathrm{~K}$ are show $\mathrm{by}$ the claracteristic lines which cross the magnet load lines. These are calculated witl a program based on the model of Green[5]. The coil and shield designs are from a high 
COMPARISON OF IRON AND SUPERCONDUCTING DIPOLE SHIELDS Load Lines and Conductor Characteriatio

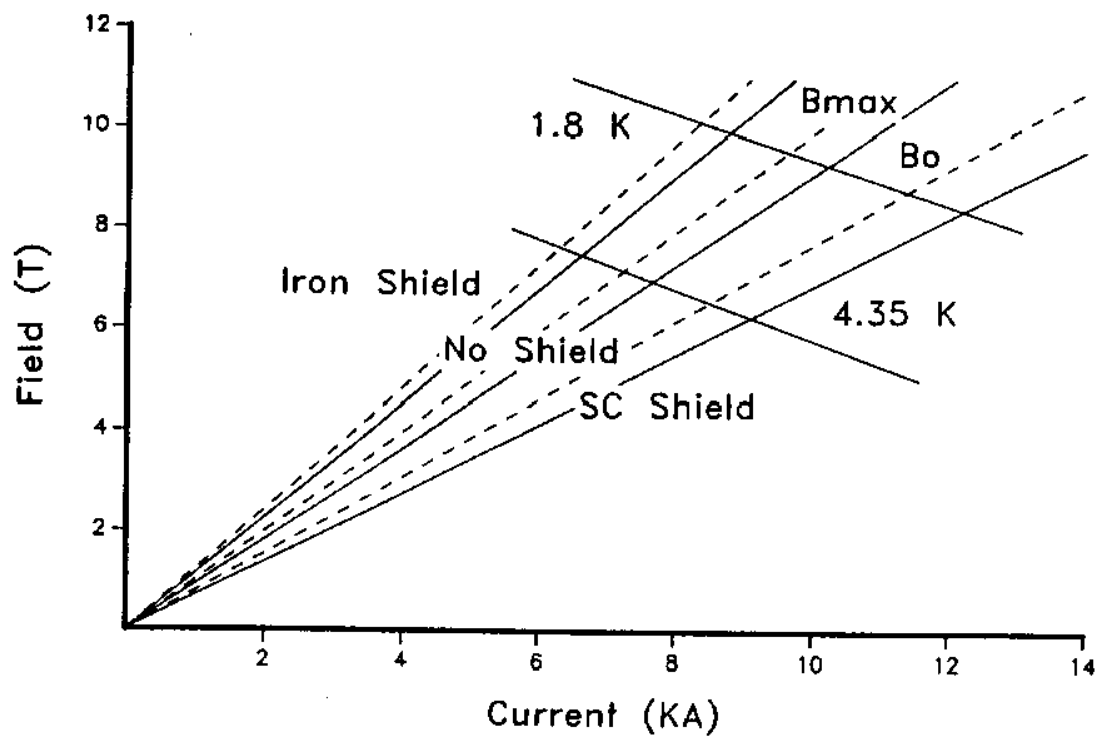

Figure 2: Operating limits for Superconducting Coils. Magnet Body Field load Lines (solid) and Load lines for Coil High Field Points (daslicd lines) and $N b l^{2} i$ Superconductor Characteristies al $4.35 \mathrm{~K}$ and $1.8 \mathrm{~K}$ are shown for three coil/shickl combinations

Table 3: Comparison of Iron and Superconducting Shields for Dipoles

\begin{tabular}{|c|c|c|c|}
\hline & $\begin{array}{l}\text { Iron } \\
\text { Shield }\end{array}$ & $\begin{array}{l}\text { Lo Ficld } \\
\text { Shield }\end{array}$ & $\begin{array}{l}\text { SC Shield } \\
\text { (Hi Field) }\end{array}$ \\
\hline Shield Radius & $9.6 \mathrm{~cm}$ & large & $9.6 \mathrm{~cm}$ \\
\hline Cable limit in Coil $(1.35 K)$ & $6.30 \mathrm{kA}$ & $7.23 \mathrm{k} \Lambda$ & $8.50 \mathrm{kA}$ \\
\hline Resulting Field at Coil & $7.64 \mathrm{~T}$ & $7.18 \mathrm{~T}$ & $6.5 .1 \mathrm{~T}$ \\
\hline Corresponding Bordy Field & $7.13 \mathrm{~T}$ & $6.58 \mathrm{~T}$ & $5.81 \top$ \\
\hline Relative Field Strengths & 1 & $0.926 \mathrm{~T}$ & 0.826 \\
\hline Cable limit in Coil $(1.8 K)$ & $8.36 \mathrm{kA}$ & $9.63 \mathrm{kA}$ & $11.39 \mathrm{kA}$ \\
\hline Resulting Field at Coil & $10.14 \mathrm{~T}$ & $9.56 \mathrm{~T}$ & $8.76^{\prime} \mathrm{T}$ \\
\hline Corresponding Body Field & $9.16 \mathrm{~T}$ & $8.76 \mathrm{~T}$ & $7.82^{\prime} \Gamma$ \\
\hline Relative Field Strengths & 1 & 0.922 & 0.818 \\
\hline Rel. Strength(Constant I) & 1 & 0.818 & 0.634 \\
\hline
\end{tabular}

field dipole design|6]. Some numerical results corresponding to Fig 2 are shown in Table 3.

These results are obtained from an analytic calculation of the fields, assuming unsaturated iron (thus the straight load lines). The magnetic field euhancement from the iron at constant current is the large factor expected (in fact, very large, since the shield radius is small enough that even at the $4.35 \mathrm{~K}$ operation, the iron shield will be saturated. The extrapolated enhancement for $1.8 K$ operation is very optimistic). However, the calculated enhancement when taking into account the conductor properties, is only about $8 \%$ when compared to a shield at large radius and oniy $18 \%$ when compared to a high field shield (only required when secking minimum rarlial aperture). A superconducting shicld at a radius corresponding to the outside iron radius will have a load line with slope siightly shallower than the "no shield" case slown. $\lambda$ calculation which accounts for the saturated iron will show somewhat less enhancement at $4.35 K$ and much less enhancement at $1.8 K$. We note that the superconducting shields will not result in any clange in field shape (harmonic content) due to saturation, unlike saturated iron shields.

In Fig 3 we illustrate the sort of geometrical differences which a superconducling shield permits for design of an accelerator dipole. The dipole with iron shield which is illustrated is typical of the SSC generation of low heat leak, cold iron superconducting dipoles. Using a high field shield permits a very compact design. Superconducting shells which shicld 1 or $2 T$ could be used in a design with this geometry. Such a geometry would provide aciequate space for the coil package to be cooled to $2 K$ with the shell held between $4 K$ and $10 K$ if that was desired for a very low temperature design. The low field design illustrates the use of $0.2 T$ superconducting shells. It is nearly as large is the designs with Iron shields, but the weight and magnetic ptoperties will have the differences outlined above.

\section{Cryostat Issues}

Since the weight involved will be 4 to 10 times less for superconducting shields than in comparable cases with iron shields, and since there will be no de-centering forces, the cryostat can be reoptimized to utilize this as an advantage. The design shown for a low field shield allows a large radial distance, such that the cryostat design can be complelely different than the folded posts which are needed to support the large iron mass. It may be possible to take advantage of the lower weights and large radial space to crcate designs in whicl the heat path can include long longitudinal distances as well as long radial ones. The much smailer mass of cold (helium temperature) materials may prove to be an very important operational advantage of supetconducting shields.

\section{Superconductor Issues}

Several issues which might be of concern need to be addressed for this system and should be examined in any proposed test. First, 
unlike Type I materials, Type II superconductors can allow fux penetration. This design presumes that onc can avoid serious fhux leakage by a suitable choice of malerials and a sufficiently conservative shield thickness. Beyond this quasi-static descriplion, one also experiences flux creep phenomena in Type ll superconductors. These effects have proved to be significaut in accelerator dipoles 7|| $8 \mid$. The flux crecp effects on the dominant field are not important (not yet observed) whereas the effects of flux crecp on field distoritions (sextupole and decapole errors) have been significant. However, for a large radius shiceld, any field sliape effects of flux crecp will be very small.

Superconducting shields are also subject to the flux jump instability[9]. This consideration will likely demand that the shield be constructed with a series of layers whose thickness is prescribed by the heat conduction and capacity of the superconductor and the host metal in which it is embedded.
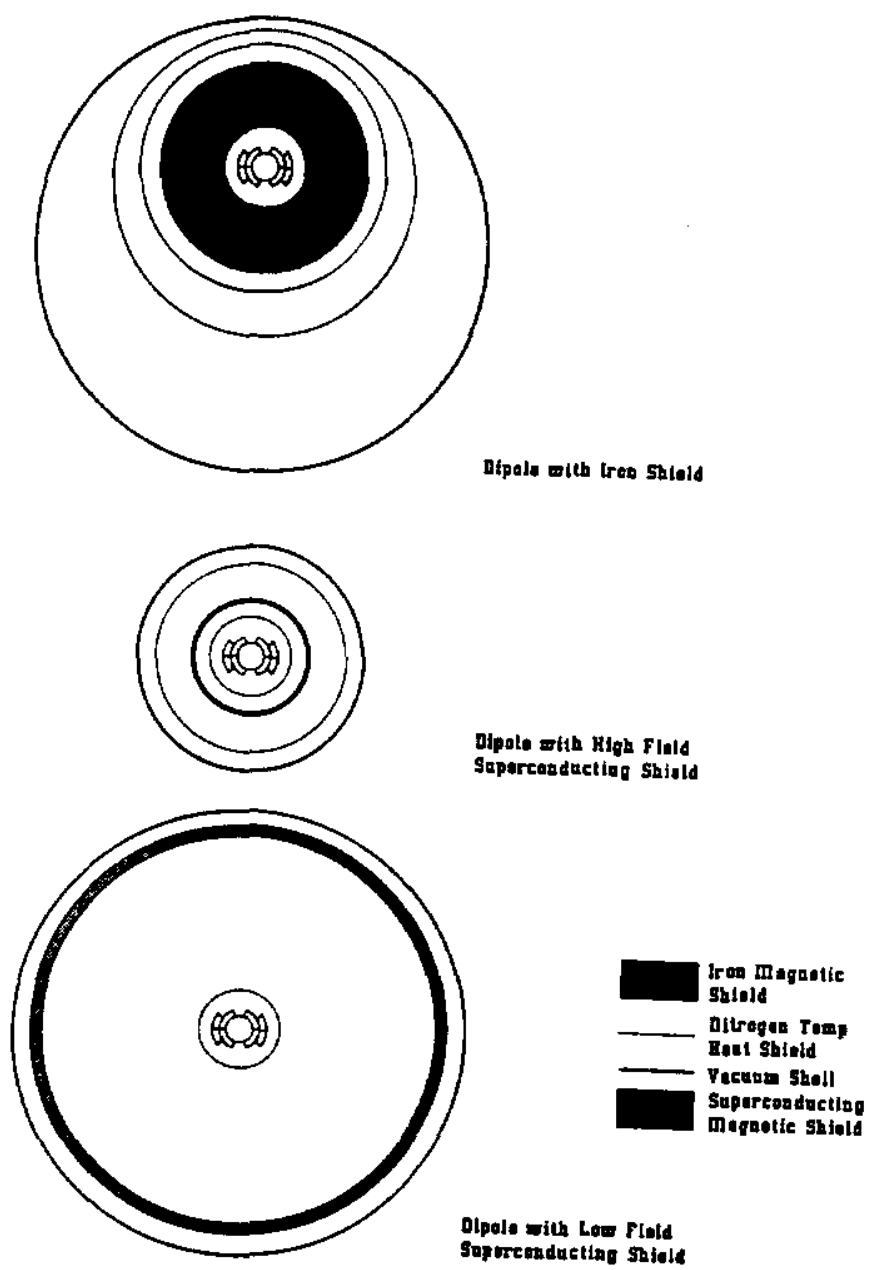

Figure 3: Comparison of Cross Sections for Dipoles with Iron shiclds and with high or low field Superconducting Shicids. The coils shown have $4 \mathrm{~cm}$ diameter and the latger vacuum shells lave a $61 \mathrm{~cm}$ diameter.

\section{Conclusions}

The possibility of a superconducting shield for acceleralor dipole and quadrupole magnets has been explored. We find that the decentering instability associated with iron shields is avoided by the strong diamagnetic shield. In addition, the shield can be much thinner, occupying less madial space in the cryosial. Wo recognize that by avoiding the weight and decentering forces of the iron shicld, we can re-optimize the cryostat design and substantially reduce the mass which must be cooled to helium temperatures.

Promising applications in which these advantages are important have been identified:

1. p-p Collider Interaction Region Quadrupoles

2. Corrector Dipoles for Collider Detectors

3. High Field Accelerator Dipoles

Perhaps this will prove to be a practical use for the new high temperature superconductors.

\section{Acknowledgements}

I would like to thank Paul Mantsch and Helen Edwards for discussions and encouragement with this work. I thank Peter Mazur for the critical discussions and essential corrections which enabled this work to proceed. Nan Riddiford and Moyses Kuchnir provided assistance with calculations.

\section{References}

1) K. Inalbach. Ficlds and first order perturbation effects in twodimensional conductor dominated magnets. Nuclear Instruments and Methods, 78:185, 1970.

[2 $\mid$ K. W. Rigby. Design of magnets inside cylindrical superconducting shields. Rev. Sci. Inslrum., 59:156, 1988.

(3) R. V. Kalashnikov, N. 13. Trusov, and A. N. Zvenigorodskaya. Magnetic shiciding of superconductors on the basis of niobiumtin compounds. Elcktrotckhnika, 55:49, 1984.

[4] SSC Central Design Group. Conceptual design of the superconducting super collider. Law rence Berkeley Laboratory, One Cyclotron Road, Berkeley, CA 94720, March 1986, SSC-SR2020.

(5) Michael A. Green. Calculating the $j_{c}, b, t$ surface for niobium titanium using a reduced-state model. IEEE Trans. on Mag., MAG-25:2119, 1989 .

[6] Fady Hafoush, Mike Harrison, Jim Kerby, Karl Koepke, Paul Mantsch, Tom Nicol, Alan Riddiford, and Jay Theilacker. The design of a large aperture high field dipole. Fermilab TM-1641, 1989.

(7) D. A. Herrup, M. J. Syphers, D. E. Johnson, R. P. Johnson, A. V. Tollestrup, R. W. ILanft, B. C. Brown, M. J. Lamm, M. Kuchnir, and A. D. McInturff. Time variations of fields in superconducting magnets and their effects on accelerators. IEEE Trans. on Mag., MAG-25:1643, 1989.

[8] R. W. Hanft B. C. Brown, D. A. Herrup, M. J. Lamm, A. D. McInturff, and M. J. Syphers. Studies of the time dependence of ficlds in tevalion superconducting dipole magnets. IEEE Trans. on Mag., MAC-25:1647, 1989.

[9] S. Sato, M. Ikeuchi, A. Iwata, Y. Saji, and S. Kado. The magnetic field screening with $n$ b-ti. In Procecding of the Ninth International Cryogenic Engineering Conference, 11-14 May 1982, Kobe, Japan, page 115. Butterworth, Guildford, Surrey, Lingland, 1982. 